\title{
Understanding Genetic Diversity of Sorghum Using Quantitative Traits
}

\author{
Sweta Sinha and N. Kumaravadivel \\ Department of Plant Molecular Biology and Biotechnology, Centre for Plant Molecular Biology, Tamil Nadu Agricultural University, \\ Coimbatore, Tamil Nadu 641003, India \\ Correspondence should be addressed to Sweta Sinha; bablysweta@gmail.com
}

Received 30 December 2015; Accepted 17 May 2016

Academic Editor: Luis T. Ortiz

Copyright (c) 2016 S. Sinha and N. Kumaravadivel. This is an open access article distributed under the Creative Commons Attribution License, which permits unrestricted use, distribution, and reproduction in any medium, provided the original work is properly cited.

\begin{abstract}
Sorghum is the important cereal crop around the world and hence understanding and utilizing the genetic variation in sorghum accessions are essential for improving the crop. A good understanding of genetic variability among the accessions will enable precision breeding. So profiling the genetic diversity of sorghum is imminent. In the present investigation, forty sorghum accessions consisting of sweet sorghum, grain sorghum, forage sorghum, mutant lines, maintainer lines, and restorer lines were screened for genetic diversity using quantitative traits. Observations were recorded on 14 quantitative traits, out of which 9 diverse traits contributing to maximum variability were selected for genetic diversity analysis. The principle component analysis revealed that the panicle width, stem girth, and leaf breadth contributed maximum towards divergence. By using hierarchical cluster analysis, the 40 accessions were grouped under 6 clusters. Cluster I contained maximum number of accessions and cluster VI contained the minimum. The maximum intercluster distance was observed between cluster VI and cluster IV. Cluster III had the highest mean value for hundred-seed weight and yield. Hence the selection of parents must be based on the wider intercluster distance and superior mean performance for yield and yield components. Thus in the present investigation quantitative data were able to reveal the existence of a wide genetic diversity among the sorghum accessions used providing scope for further genetic improvement.
\end{abstract}

\section{Introduction}

Sorghum (Sorghum bicolor) is the world's fifth most important cereal, after wheat, rice, maize, and barley $[1,2]$. It is a major food crop in Sub-Saharan Africa and South Asia and is the staple food for the most food insecure people in the world [3]. Besides being an important food, feed, and forage crop, it provides raw material for the production of starch, fiber, dextrose syrup, biofuels, alcohol, and other products. Sorghum was domesticated in African continent, particularly in Ethiopia, from where it was introduced to other regions of the world with diverse agroclimatic conditions [4]. Therefore a wide diversity is found within and among the sorghum cultivars at both phenotypic and genotypic level $[5,6]$. Knowledge of genetic diversity of a crop usually helps the breeder in choosing desirable parents for the breeding program and gene introgression from distantly related germplasm. The more diverse genotypes or accessions can be crossed to produce superior hybrids with resistance to abiotic and biotic stresses. Understanding the wealth of genetic diversity in sorghum will facilitate further improvement of this crop for its genetic architecture [7].

Genetic diversity in the crop species is the gift of nature and arises due to geographical separation or due to genetic barriers to crossability. Morphological traits are conventional tools to analyze the genetic diversity. Morphological assays generally require neither sophisticated equipment nor preparatory procedures. They are generally simple and inexpensive to score. These easily observable quantitative morphological traits are useful tool for preliminary evaluation, because they offer a fast and useful approach for assessing the extent of diversity. Over the years, a number of studies have dealt with estimating genetic diversity in cultivated sorghum using morphological traits [8-14]. The use of morphological traits is the most common approach utilized to estimate relationships between genotypes. The genetic variability of 
cultivated species/varieties and their wild relatives together forms a potential and continued source for breeding new and improved crop varieties. A better understanding of genetic diversity in sorghum will facilitate crop improvement. Therefore there is a need to evaluate the available accessions for genetic diversity. In the present study, an attempt has been made to determine the extent of diversity among forty sorghum accessions using the quantitative traits.

\section{Materials and Methods}

2.1. Plant Material. The plant materials consisted of forty accessions of sorghum collected from different parts of Tamil Nadu (Table 1). Among these forty accessions, four of accessions were sweet sorghum, seventeen were grain sorghum, two were forage sorghum, ten were mutant populations, three were B-lines, and the remaining four accessions were R-lines.

2.2. Methods. The forty sorghum accessions were raised in a randomized block design (RBD) with two replications for one season at Millet Breeding Station, TNAU, Coimbatore, Tamil Nadu. Each accession was raised in a single row of 5 meters length by adopting a spacing of $45 \mathrm{~cm} \times 15 \mathrm{~cm}$. All the recommended agronomic packages of practices such as irrigation, fertilizer doses, and crop protection management were adopted during the entire crop period. In each replication, five random plants were chosen and the observations were recorded on fourteen quantitative traits at the time of maturity except days to 50 percent flowering. Observations consisted of days to $50 \%$ flowering (DFL), days to maturity (DMY), plant height (PHT), panicle length (PNL), panicle width (PWD), leaf length (LFL), leaf breadth (LFW), number of leaves per plant (NPL), stem girth (SGT), number of primary branches per panicle (NPB), hundred-seed weight (HWT), yield per plant (YLD), panicle weight (PWT), and dry matter production (DMP). The mean values were utilized for statistical analysis to assess the genetic diversity among the accessions.

2.3. Statistical Analysis of Quantitative Traits. Prior to analysis the data were standardized to zero mean and unit variance, because various traits were measured on very different scales. The descriptive statistics, analysis of variance, and correlation coefficients were computed for all the fourteen quantitative traits using Microsoft Excel 2003. Factor analysis was performed to know which trait is contributing maximum variability. Principal component analysis of the traits was employed to examine the percentage contribution of each trait to total genetic variation. Agglomerative hierarchical clustering was performed on the Euclidean distance matrix utilizing Ward's linkage method. These analyses were done using MINITAB software version 13.

\section{Result and Discussion}

The analysis of variance using a randomized block design indicated significant variation for all 14 quantitative traits (result not shown) investigated indicating that there was a high level of genetic diversity among the sorghum accessions.

3.1. Descriptive Statistics. Statistical analysis was carried out with the data on fourteen quantitative traits to assess the variability pattern (Table 2). Among all the traits investigated, dry matter production recorded maximum value of mean, standard error, variance, standard deviation, coefficient of variation, and range. The descriptive statistics of fourteen quantitative indicated the existence of morphological diversity among the sorghum accessions, providing scope for improvement through hybridization and selection. The coefficient of variation for yield, panicle weight, and dry matter production were high denoting susceptibility to environmental fluctuation influencing their expression to some degree.

3.2. Correlation Analysis. The correlation coefficients of fourteen quantitative traits were used in characterizing the forty sorghum accessions. The correlation coefficients of fourteen quantitative traits estimated are presented in Table 3. The high positive and significant correlation value was obtained for panicle weight and hundred-seed weight with yield $[15,16]$. The yield was also positively and significantly associated with leaf length, leaf breadth, and number of leaves. Leaf length, leaf breadth, and number of leaves could contribute to quantity of food synthesized by the plant during photosynthesis and have direct effects on yield. From these results it is evident that these traits are associated with grain yield and are intercorrelated among them. Thus, the selection in any one of these yield attributing traits will lead to increase in the other traits, thereby finally enhancing the grain yield. Hence, selection for traits like leaf length, leaf breadth, number of leaves per plant, panicle weight, and hundred-seed weight may also be given importance along with yield.

3.3. Factor Analysis. Factor analysis was performed in order to reduce a large set of phenotypic traits to a more meaningful smaller set of traits and to know which trait is contributing to maximum variability because genetic improvement depends on the magnitude of genetic variation. Factor analysis provides an exact picture of variability contributed to by each trait. Thus, on the basis of factor analysis, the quantitative traits that are contributing maximum variability to the first three factors are selected for principal component analysis (Table 4). The first three factors are contributing to 57\% of the total variance observed. The first factor had high contributing factor loading from stem girth, leaf breadth, leaf length, number of leaves per plant, and number of primary branches per panicle and contributed to $20.1 \%$ of the total variation. The second factor had high contributing loading from yield, panicle weight, and hundred-seed weight and contributed to $19.2 \%$ of the total variation. The third factor had high contributing loading from panicle length, panicle width, plant height, hundred-seed weight, and leaf length and contributed to $17.7 \%$ of total variation. Distribution of biometrical traits in first two factors is shown in loading plot (Figure 1). The loading plot clearly showed that the traits days to maturity, panicle length, days to 50 percent flowering, 


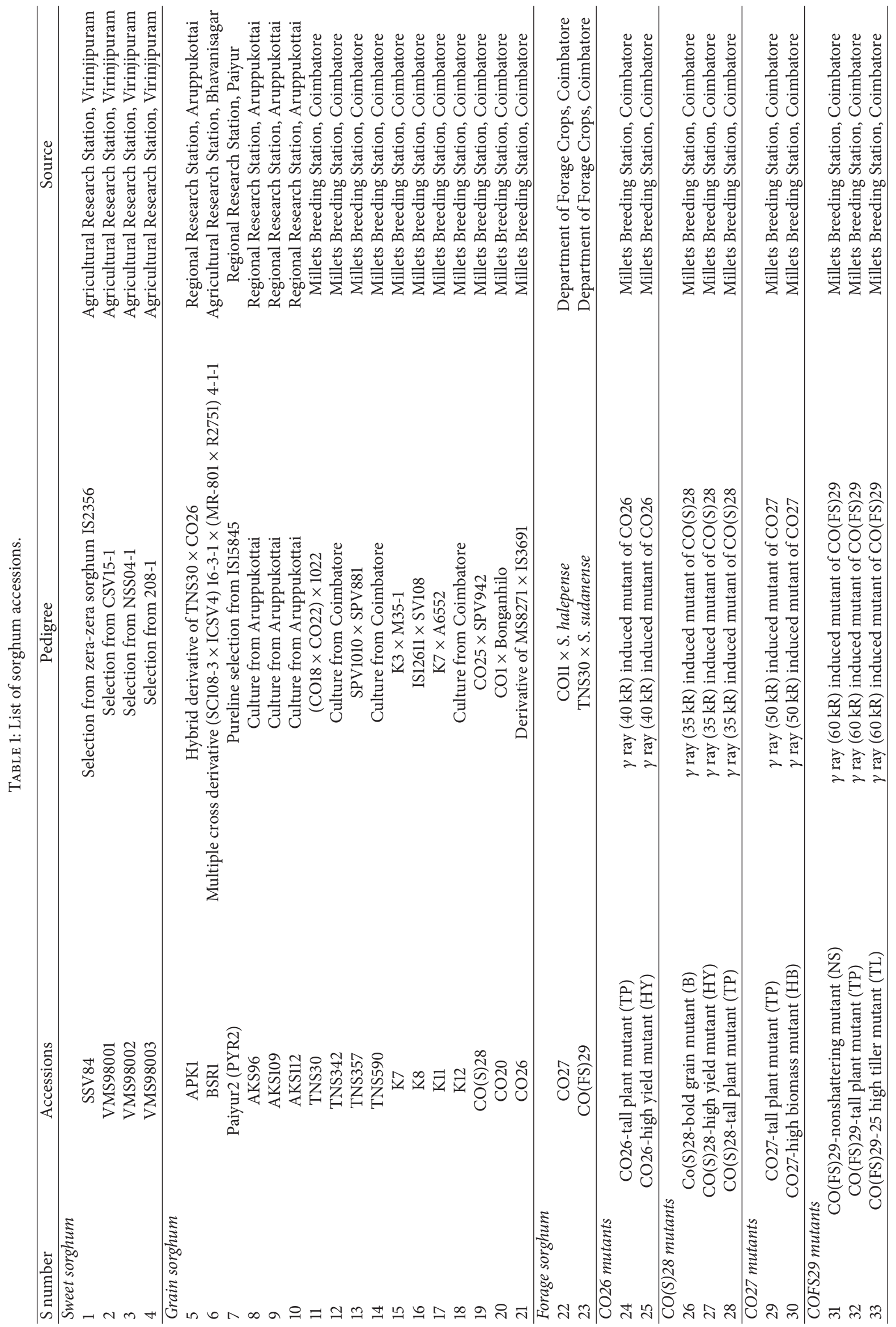




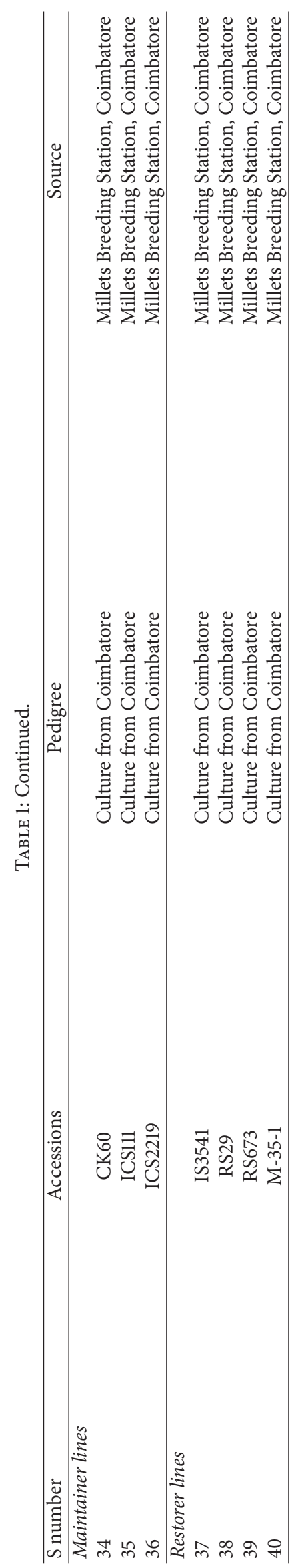


TABLE 2: Descriptive statistics of quantitative traits.

\begin{tabular}{lcccccccccccccc}
\hline & DFL & DMY & PHT & PNL & PWD & LFL & LFW & NPL & SGT & NPB & HWT & YLD & PWT & DMP \\
\hline Mean & 66.20 & 104.66 & 182.99 & 24.91 & 7.07 & 62.26 & 6.76 & 8.72 & 4.69 & 47.29 & 2.30 & 35.66 & 47.97 & 450.36 \\
Standard error & 0.88 & 0.83 & 7.50 & 1.10 & 0.33 & 1.85 & 0.26 & 0.13 & 0.16 & 1.62 & 0.14 & 1.83 & 2.18 & 27.75 \\
Standard deviation & 5.59 & 5.26 & 47.44 & 6.95 & 2.08 & 11.68 & 1.66 & 0.80 & 1.03 & 10.23 & 0.86 & 11.58 & 13.76 & 175.49 \\
Sample variance & 31.22 & 27.67 & 2250.37 & 48.27 & 4.32 & 136.50 & 2.77 & 0.65 & 1.06 & 104.57 & 0.74 & 134.14 & 189.31 & 30797.12 \\
Range & 26.00 & 24.00 & 209.60 & 30.90 & 9.95 & 55.05 & 6.55 & 4.05 & 3.80 & 47.50 & 3.45 & 41.50 & 52.00 & 673.50 \\
Coefficient of variation & 8.44 & 5.03 & 25.92 & 27.89 & 29.43 & 18.77 & 24.62 & 9.22 & 21.96 & 21.62 & 37.37 & 32.47 & 28.68 & 38.97 \\
\hline
\end{tabular}

TABLE 3: Pearson's correlation coefficients of quantitative traits.

\begin{tabular}{|c|c|c|c|c|c|c|c|c|c|c|c|c|c|}
\hline & DFL & DMY & PHT & PNL & PWD & LFL & LFW & NPL & SGT & NPB & HWT & YLD & PWT \\
\hline DMY & $0.752^{* *}$ & & & & & & & & & & & & \\
\hline PHT & -0.011 & -0.241 & & & & & & & & & & & \\
\hline PNL & 0.058 & 0.021 & $0.580^{* *}$ & & & & & & & & & & \\
\hline PWD & -0.054 & -0.186 & $0.564^{* *}$ & $0.596^{* *}$ & & & & & & & & & \\
\hline LFL & 0.069 & -0.184 & 0.159 & 0.253 & $0.386^{*}$ & & & & & & & & \\
\hline LFW & 0.126 & 0.035 & -0.265 & -0.076 & 0.137 & $0.578^{* *}$ & & & & & & & \\
\hline NPL & 0.278 & 0.263 & -0.072 & 0.008 & 0.052 & 0.252 & $0.564^{* *}$ & & & & & & \\
\hline SGT & 0.060 & 0.104 & -0.180 & 0.051 & 0.264 & $0.477^{* *}$ & $0.741^{* *}$ & $0.576^{* *}$ & & & & & \\
\hline NPB & -0.048 & -0.299 & 0.156 & -0.171 & 0.120 & 0.282 & $0.525^{* *}$ & 0.309 & $0.319^{*}$ & & & & \\
\hline HWT & 0.221 & 0.227 & $-0.440^{* *}$ & $-0.408^{* *}$ & -0.189 & 0.121 & $0.649^{* *}$ & $0.455^{* *}$ & $0.352^{*}$ & $0.343^{*}$ & & & \\
\hline YLD & 0.230 & 0.121 & -0.147 & 0.013 & 0.021 & $0.361^{*}$ & $0.525^{* *}$ & $0.547^{* *}$ & 0.292 & 0.235 & $0.668^{* *}$ & & \\
\hline PWT & 0.305 & 0.138 & -0.131 & -0.070 & -0.018 & $0.320^{*}$ & $0.521^{* *}$ & $0.537^{* *}$ & 0.286 & 0.286 & $0.707^{* *}$ & $0.961^{* *}$ & \\
\hline DMP & 0.153 & 0.002 & $0.327^{*}$ & -0.064 & 0.212 & 0.078 & 0.187 & 0.254 & 0.176 & 0.271 & $0.320^{*}$ & 0.264 & $0.325^{*}$ \\
\hline
\end{tabular}

${ }^{*} P<0.05,{ }^{* *} P<0.01$.

TABLE 4: Sorted rotated factor loadings of quantitative traits.

\begin{tabular}{lccc}
\hline Variable & Factor 1 & Factor 2 & Factor 3 \\
\hline Stem girth & 0.908 & -0.057 & -0.048 \\
Leaf breadth & 0.858 & -0.371 & 0.089 \\
Leaf length & 0.602 & -0.291 & -0.431 \\
Number of leaves per plant & 0.565 & -0.384 & 0.005 \\
Yield & 0.217 & -0.955 & -0.019 \\
Panicle weight & 0.202 & -0.939 & 0.038 \\
Hundred-seed weight & 0.364 & -0.636 & 0.459 \\
Panicle length & -0.009 & 0.002 & -0.885 \\
Panicle width & 0.253 & 0.058 & -0.796 \\
Plant height & -0.227 & 0.129 & -0.786 \\
Days to maturity & 0.029 & -0.04 & 0.128 \\
Days to 50\% flowering & 0.045 & -0.178 & -0.052 \\
Dry matter production & 0.035 & -0.209 & -0.11 \\
Number of primary & 0.476 & -0.122 & 0.071 \\
branches per panicle & 2.81 & 2.685 & 2.479 \\
Variance & 20.1 & 19.2 & 17.7 \\
\% variance & 20.1 & 39.3 & 57.0 \\
Cumulative \% variance & & & \\
\hline
\end{tabular}

panicle weight, and dry matter production had contributed low variability towards genetic variation.
TABLE 5: Principal components analysis showing the contribution of 9 characters among the sorghum accessions.

\begin{tabular}{lccc}
\hline Traits & PC1 & PC2 & PC3 \\
\hline Stem girth & 0.396 & -0.113 & 0.486 \\
Leaf breadth & 0.477 & -0.004 & 0.146 \\
Leaf length & 0.302 & -0.353 & 0.281 \\
Number of leaves per plant & 0.381 & 0.024 & -0.083 \\
Number of primary branches per panicle & 0.286 & -0.158 & -0.055 \\
Yield per plant & 0.371 & 0.117 & -0.317 \\
Hundred-seed weight & 0.377 & 0.336 & -0.256 \\
Panicle width & 0.078 & -0.602 & 0.097 \\
Plant height & -0.112 & -0.59 & -0.426 \\
Eigenvalue & 3.753 & 1.96 & 0.876 \\
\% variance & 41.7 & 21.8 & 9.7 \\
Cumulative \% variance & 41.7 & 63.5 & 73.2 \\
\hline
\end{tabular}

3.4. Principal Component Analysis. A set of nine diverse quantitative traits were selected from the fourteen traits, namely, stem girth, leaf breadth, leaf length, number of leaves per plant, number of primary branches per panicle, yield, hundred-seed weight, panicle width, and plant height, and were used to group the accessions based on principal component. The first three principal components accounted for $73.2 \%$ of the total variance (Table 5). The first principal component (PC1) accounted for $41.7 \%$ of total variance and had high contributing factor loading from leaf breadth, stem 
TABLE 6: Intercluster distances among sorghum accessions.

\begin{tabular}{|c|c|c|c|c|c|c|}
\hline & Cluster I & Cluster II & Cluster III & Cluster IV & Cluster V & Cluster VI \\
\hline Cluster I & 0.000 & & & & & \\
\hline Cluster II & 2.813 & 0.000 & & & & \\
\hline Cluster III & 2.343 & 2.133 & 0.000 & & & \\
\hline Cluster IV & 5.088 & 2.955 & 4.168 & 0.000 & & \\
\hline Cluster V & 5.125 & 3.823 & 4.827 & 4.705 & 0.000 & \\
\hline Cluster VI & 4.260 & 3.105 & 4.150 & 5.148 & 3.188 & 0.000 \\
\hline
\end{tabular}

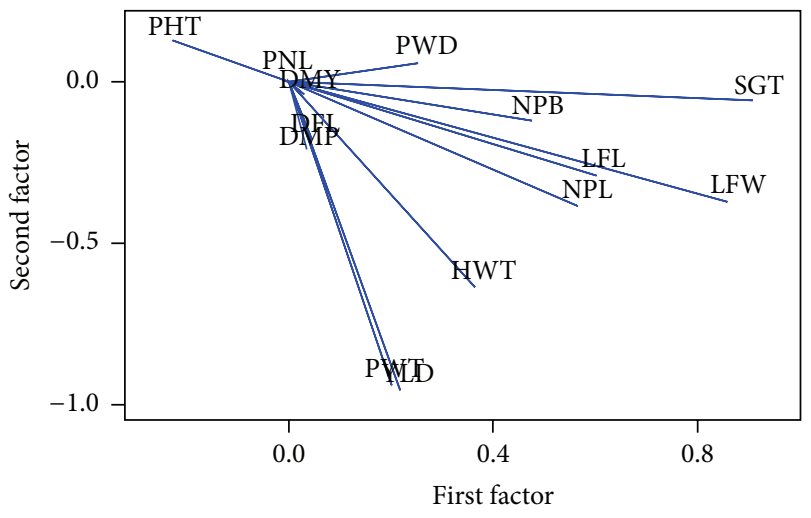

FIGURE 1: Loading plot of quantitative traits based on factor analysis.

girth, number of leaves per plant, hundred-seed weight, and yield. The second principal component (PC2) had high contributing factor loading from panicle width, plant height, leaf length, and hundred-seed weight and contributed to $21.8 \%$ of the total variation. The third principal component (PC3) accounted for $9.7 \%$ of the total variation, with high factor loading for number of primary branches per panicle, stem girth, plant height, yield, and leaf length. The PCA analysis revealed that the panicle width, stem girth, and leaf breadth contributed maximum towards divergence. The score plot of 40 accessions based on the first two principal components is presented in Figure 2. Accessions from similar geographical locations were distributed in different groups. This was exhibited by the accessions of Virinjipuram, Aruppukottai, and Coimbatore. The distribution pattern also indicated the existence of significant amount of variability among the grain sorghum.

3.5. Cluster Analysis. Agglomerative hierarchical clustering performed on the Euclidean distance matrix utilizing Ward's linkage method and resulting dendrogram is presented in Figure 3. The forty sorghum accessions formed six clusters at $25.04 \%$ similarity level. Among the different clusters, the cluster size varied from 3 to 12 . The maximum number of accessions was included in cluster I having 12 accessions and the minimum number in cluster VI having 3 accessions. Cluster I consisted of sweet sorghum, grain sorghum, and restorer lines. Cluster II consisted of sweet sorghum, grain sorghum, and $\mathrm{CO}(\mathrm{S}) 28$ mutants. Cluster III consisted of grain sorghum, restorer lines, and $\mathrm{CO} 26$ mutant and $\mathrm{CO}(\mathrm{S}) 28$ mutant. Cluster IV consisted of grain sorghum and maintainer lines. Cluster V and cluster VI consisted of forage sorghum and its mutant. The clustering pattern indicated the existence of significant amount of variability among the grain sorghum. The existence of morphological variation was found among sorghum accessions collected from eastern parts of Ethiopia using 10 morphological traits and variation among the sorghum germplasm [17]. The morphological diversity was observed among sorghum accessions as well as a high level of diversity within each region and was distributed with geographical origin using Sudanese sorghum landraces [18]. Also a high level of morphological and genetic variability was found in sorghum varieties from Burkina Faso [19].

The highest intercluster distance was observed between cluster IV and VI (5.148); the accessions from those clusters if chosen for hybridization program may give broad spectrum of variability in segregating generation (Table 6). The lowest intercluster distance was observed between II and III (2.133). The clusters contributing maximum to the divergence were given greater emphasis for deciding the type of cluster for the purpose of further selection and the choice of the parents of hybridization [20].

The cluster mean of the six similarity cluster groups in the 40 sorghum accessions are presented in Table 7. Cluster I had the highest mean values for leaf length (71.17), leaf breadth (8.41), number of leaves per plant (9.42), and stem girth (5.84). Cluster II showed moderate mean values for leaf length, leaf width, stem girth, and hundred-seed weight. Cluster III had the highest mean values for hundred-seed weight (2.99) and yield (50.00). Cluster IV had the lowest mean values for plant height (97.03) and panicle width (4.00). Cluster V had the highest mean values for panicle width (9.26). Cluster VI had the highest mean values for plant height (255.92) and number of primary branches per panicle (59.83). Based on the cluster means, the important cluster is cluster III which had the highest mean values for hundred-seed weight and yield. Hence the accessions falling under these clusters could be used as the parents for hybridization program.

\section{Conclusion}

This study supports that quantitative traits are useful tool for preliminary evaluation of genetic diversity. Correlation studies clearly showed that the traits, namely, leaf length, leaf breadth, number of leaves per plant, panicle weight, and hundred-seed weight, had significant and positive association with yield. The principle component analysis and hierarchical cluster analysis grouped the sorghum accessions under six 
TABLE 7: Characteristic means of six similarity cluster groups of sorghum accessions.

\begin{tabular}{|c|c|c|c|c|c|c|}
\hline Traits & $\mathrm{I}$ & II & III & IV & $\mathrm{V}$ & VI \\
\hline Plant height & 178.40 & 164.68 & 181.16 & 97.03 & 254.45 & 255.92 \\
\hline Panicle width & 7.98 & 6.61 & 5.78 & 4.00 & 9.26 & 7.33 \\
\hline Leaf length & 71.17 & 57.54 & 62.76 & 46.13 & 56.74 & 69.40 \\
\hline Leaf breadth & 8.41 & 6.76 & 6.74 & 5.36 & 3.54 & 6.50 \\
\hline Number of leaves per plant & 9.42 & 8.28 & 9.14 & 8.13 & 8.15 & 7.82 \\
\hline Stem girth & 5.84 & 4.37 & 4.31 & 4.14 & 3.36 & 4.05 \\
\hline Number of primary branches per panicle & 50.50 & 49.00 & 50.79 & 32.00 & 34.81 & 59.83 \\
\hline Hundred-seed weight & 2.68 & 2.59 & 2.99 & 1.94 & 0.60 & 1.17 \\
\hline Yield per plant & 42.39 & 30.63 & 50.00 & 25.79 & 26.13 & 21.67 \\
\hline
\end{tabular}

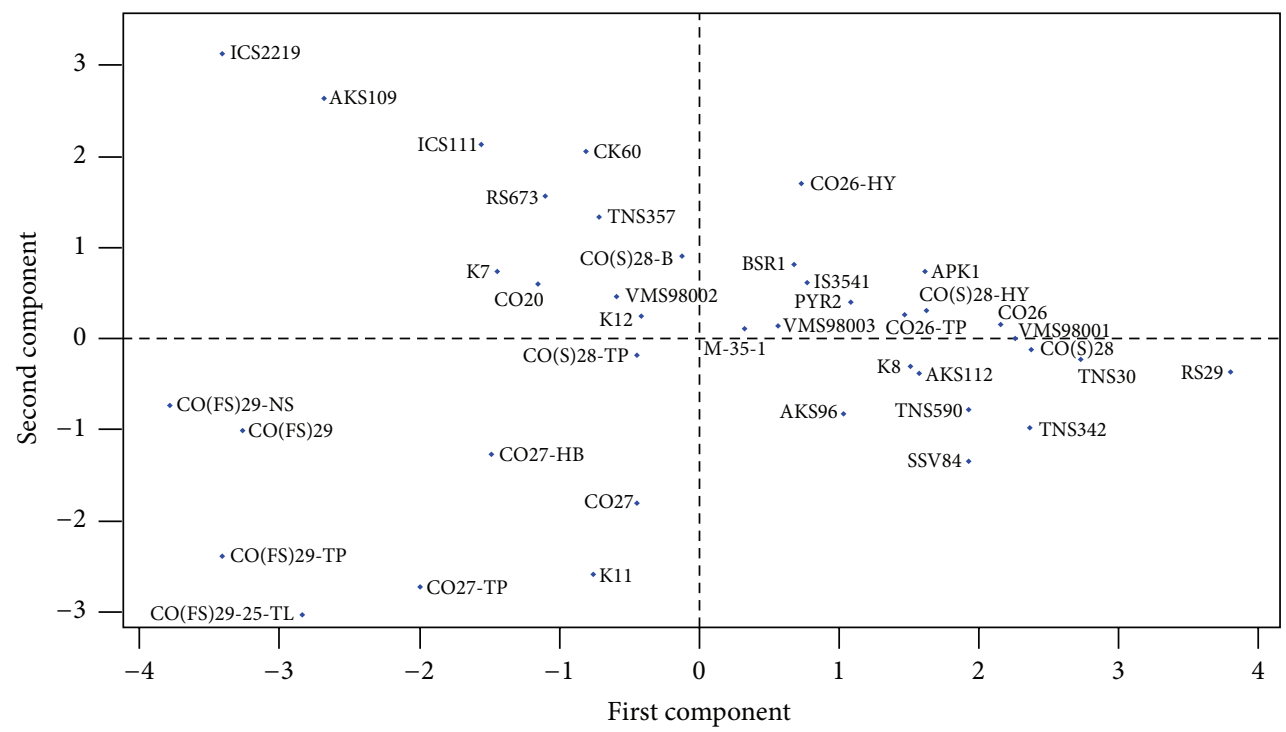

FIGURE 2: Distribution of sorghum accessions for first two principal components based on nine quantitative traits.



FIGURE 3: Dendrogram of sorghum accessions based on nine quantitative traits. 
clusters. Hence, selection of parents must be based on the wider intercluster distance and superior mean performance for yield and yield components. Based on the quantitative trait data, the accessions, namely, CO20 and Paiyur2, were found to be superior for earliness and APK1 and CO26high yield mutant for grain yield. Therefore these accessions should be utilized in further breeding program for developing superior varieties.

\section{Disclosure}

Department of Molecular Biology and Genetic Engineering, Bihar Agricultural University, Sabour, Bhagalpur, Bihar 813210 , India, is the present address of Sweta Sinha.

\section{Competing Interests}

The authors declare that they have no competing interests.

\section{References}

[1] K. B. Ritter, C. L. McIntyre, I. D. Godwin, D. R. Jordan, and S. C. Chapman, "An assessment of the genetic relationship between sweet and grain sorghums, within Sorghum bicolor ssp. bicolor (L.) Moench, using AFLP markers," Euphytica, vol. 157, no. 1-2, pp. 161-176, 2007.

[2] T. Motlhaodi, M. Geleta, T. Bryngelsson, M. Fatih, S. Chite, and R. Ortiz, "Genetic diversity in ex-situ conserved sorghum accessions of Botswana as estimated by: microsatellite markers," Australian Journal of Crop Science, vol. 8, no. 1, pp. 35-43, 2014.

[3] A. Bibi, H. A. Sadaqat, H. M. Akram, and M. I. Mohammed, "Physiological markers for screening sorghum (Sorghum bicolor) germplasm under water stress condition," International Journal of Agriculture and Biology, vol. 12, no. 3, pp. 451-455, 2010.

[4] R. Li, H. Zhang, X. Zhou et al., "Genetic diversity in Chinese sorghum landraces revealed by chloroplast simple sequence repeats," Genetic Resources and Crop Evolution, vol. 57, no. 1, pp. $1-15,2010$.

[5] L. Kong, J. Dong, and G. E. Hart, "Characteristics, linkagemap positions, and allelic differentiation of Sorghum bicolor (L.) Moench DNA simple-sequence repeats (SSRs)," Theoretical and Applied Genetics, vol. 101, no. 3, pp. 438-448, 2000.

[6] G. E. Hart, K. F. Schertz, Y. Peng, and N. H. Syed, "Genetic mapping of Sorghum bicolor (L.) Moench QTLs that control variation in tillering and other morphological characters," Theoretical and Applied Genetics, vol. 103, no. 8, pp. 1232-1242, 2001.

[7] M. Jayaramachandran, N. Kumaravadivel, G. Kandasamy, and S. Eapen, "Comparison of genetic variability induced by $\gamma$ radiation and tissue culture in sorghum," International Journal of Bio-resource and Stress Management, vol. 2, no. 3, pp. 329-333, 2011.

[8] J.-D. Zongo, P. H. Gouyon, and M. Sandmeier, "Genetic variability among sorghum accessions from the Sahelian agroecological region of Burkina Faso," Biodiversity and Conservation, vol. 2, no. 6, pp. 627-636, 1993.

[9] R. S. Appa, P. Rao, M. H. Mengesha, and V. G. Reddy, "Morphological diversity in sorghum germplasm from India," Genetic Resources and Crop Evolution, vol. 43, no. 6, pp. 559567, 1996.
[10] A. Ayana and E. Bekele, "Geographical patterns of morphological variation in sorghum (Sorghum bicolor (L.) Moench) germplasm from Ethiopia and Eritrea: qualitative characters," Hereditas, vol. 129, no. 3, pp. 195-205, 1998.

[11] L. S. Kumar, "DNA markers in plant improvement: an overview," Biotechnology Advances, vol. 17, no. 2-3, pp. 143-182, 1999.

[12] J. A. Dahlberg, X. Zhang, G. E. Hart, and J. E. Mullet, "Comparative assessment of variation among sorghum germplasm accessions using seed morphology and RAPD measurements," Crop Science, vol. 42, no. 1, pp. 291-296, 2002.

[13] T. Shehzad, H. Okuizumi, M. Kawase, and K. Okuno, "Development of SSR-based sorghum (Sorghum bicolor (L.) Moench) diversity research set of germplasm and its evaluation by morphological traits," Genetic Resources and Crop Evolution, vol. 56, no. 6, pp. 809-827, 2009.

[14] A. Adugna, "Analysis of in situ diversity and population structure in Ethiopian cultivated Sorghum bicolor (L.) landraces using phenotypic traits and SSR markers," SpringerPlus, vol. 3, no. 1, pp. 1-14, 2014.

[15] B. R. Bakheit, "Variability and correlations in grain sorghum genotypes under drought conditions at different stages of growth," Asian Journal of Agricultural Sciences, vol. 20, no. 4, pp. 227-252, 1989.

[16] N. Senthil and S. Palanisamy, "Character association and path analysis in sorghum," The Madras Agricultural Journal, vol. 82, pp. 169-170, 1995.

[17] N. Geleta and M. T. Labuschagne, "Qualitative traits variation in sorghum (Sorghum bicolor (L.) Moench) germplasm from eastern highlands of Ethiopia," Biodiversity and Conservation, vol. 14, no. 13, pp. 3055-3064, 2005.

[18] C. Grenier, P. J. Bramel, J. A. Dahlberg et al., "Sorghums of the Sudan: analysis of regional diversity and distribution," Genetic Resources and Crop Evolution, vol. 51, no. 5, pp. 489-500, 2004.

[19] C. Barro-Kondombo, F. Sagnard, J. Chantereau et al., "Genetic structure among sorghum landraces as revealed by morphological variation and microsatellite markers in three agroclimatic regions of Burkina Faso," Theoretical and Applied Genetics, vol. 120, no. 8, pp. 1511-1523, 2010.

[20] M. M. Rohman, M. A. Hakim, N. A. Sultana, M. E. Kabir, M. H. Hasanuzzan, and M. Ali, "Genetic divergence analysis in sorghum (Sorghum bicolor L.)," Asian Journal of Plant Sciences, vol. 3, no. 2, pp. 211-214, 2004. 


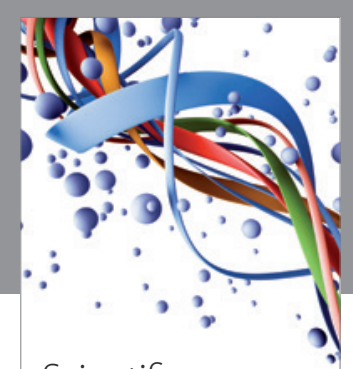

Scientifica

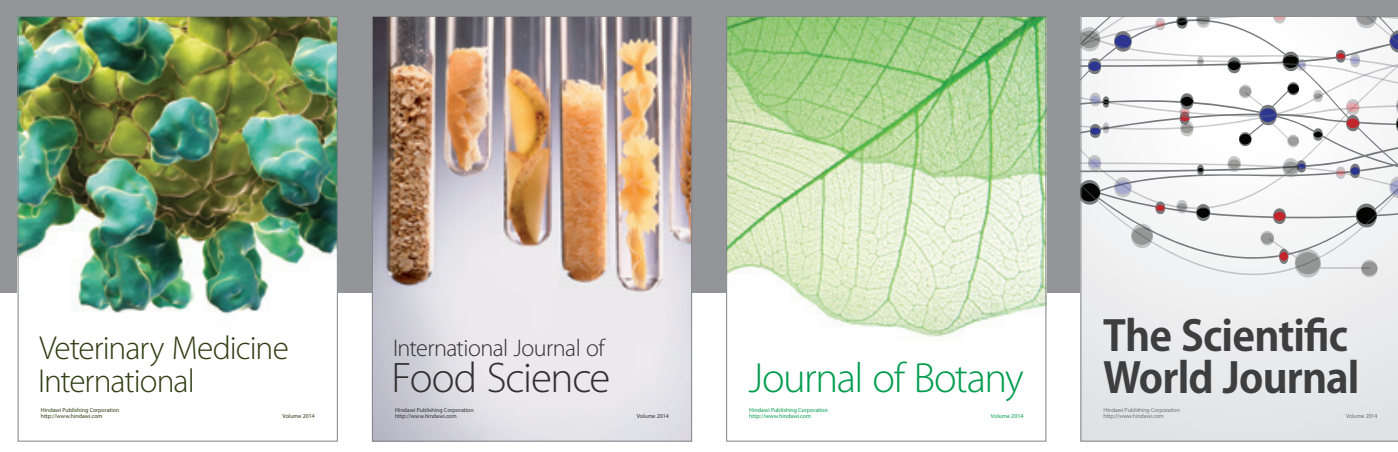

The Scientific

\section{World Journal}

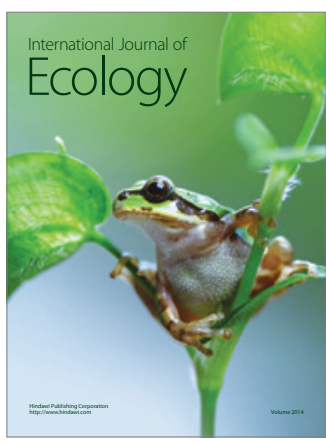

\section{Hindawi}

Submit your manuscripts at

http://www.hindawi.com
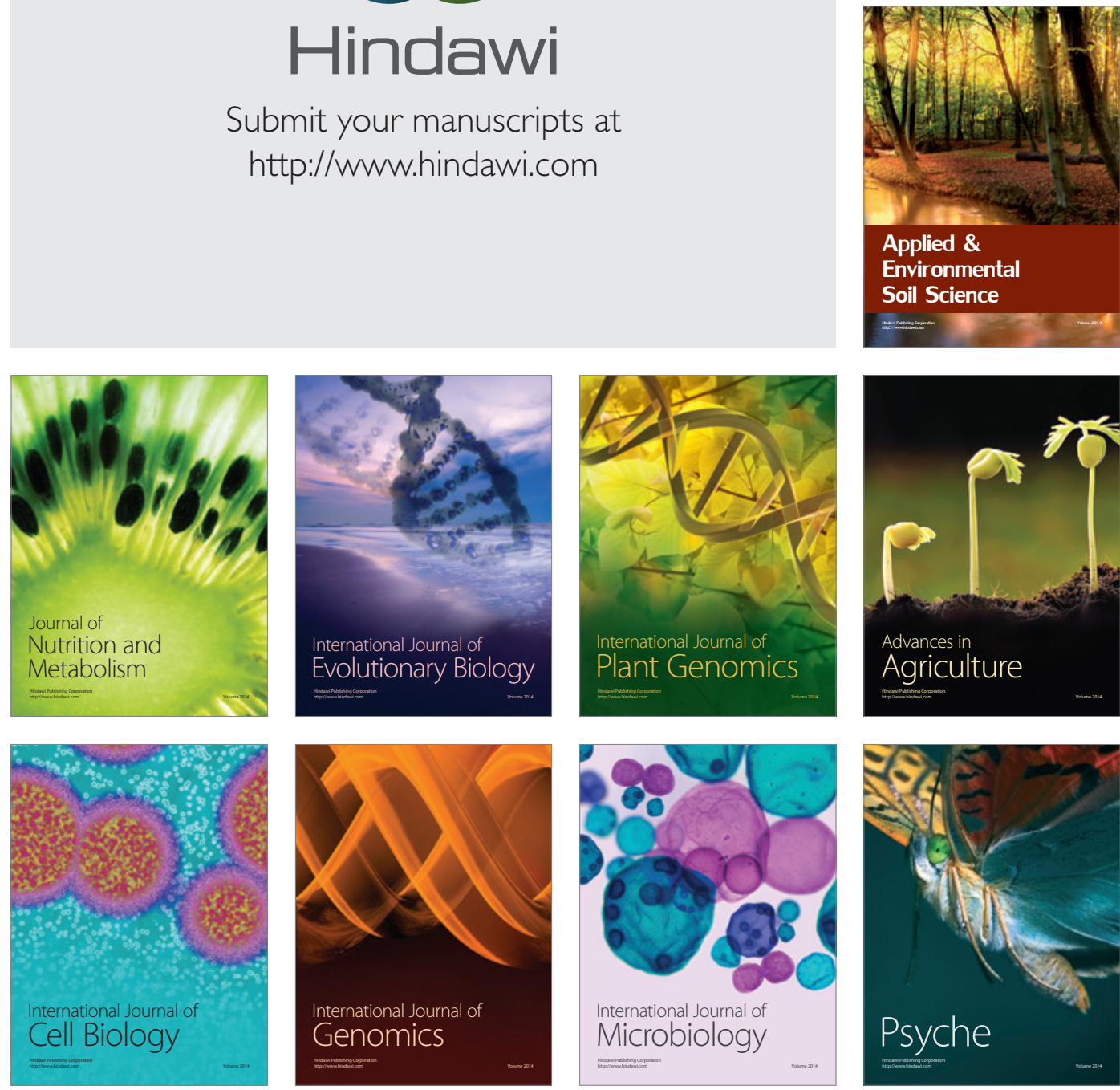
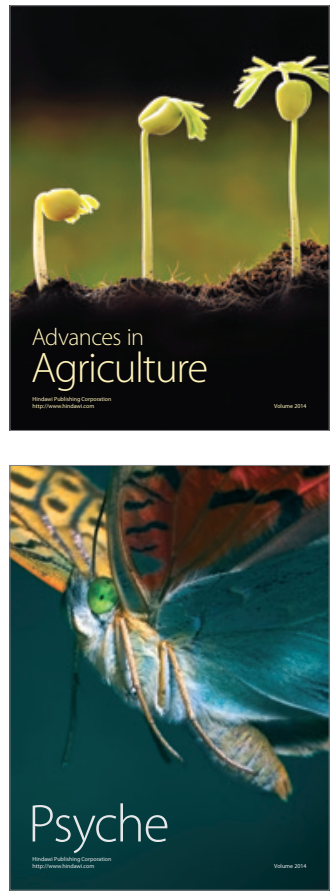